\title{
Treatment Outcomes and Predictors of Outcome in Multidrug Resistance Tuberculosis (MDR-TB) Cohort of Patients in Addis Ababa, Ethiopia
}

\author{
Netsanet Aragaw ${ }^{1}$, Mekonnen Teferi ${ }^{1,}{ }^{*}$, Oumer Ali ${ }^{1}$, Emawayish Tesema ${ }^{2}$, Samuel Ayele ${ }^{1}$, \\ Habtamu Jarso ${ }^{3}$, Kifle Woldemichael ${ }^{3}$ \\ ${ }^{1}$ Armauer Hansen Research Institute, Addis Ababa, Ethiopia \\ ${ }^{2}$ All Africa Leprosy, Tuberculosis and Rehabilitation Training Centre, Addis Ababa, Ethiopia \\ ${ }^{3}$ Department of Epidemiology, College of Health Science, Jimma University, Jimma, Ethiopia

\section{Email address:} \\ netsuhe2014@yahoo.com (N. Aragaw),mekonnen.teferi@ahri.gov.et (M. Teferi),oumer2003@gmail.com (O. Ali), \\ emawayishtesema@ymail.com (E. Tesema),sam4hi@gmail.com (S. Ayele), hjarso@rocketmail.com(H. Jarso), \\ bethy_kifle@yahoo.com (K. Woldemichael) \\ ${ }^{*}$ Corresponding author
}

\section{To cite this article:}

Netsanet Aragaw, Mekonnen Teferi, Oumer Ali, Emawayish Tesema, Samuel Ayele, Habtamu Jarso, Kifle Woldemichael. Treatment Outcomes and Predictors of Outcome in Multidrug Resistance Tuberculosis (MDR-TB) Cohort of Patients in Addis Ababa, Ethiopia. American Journal of Health Research. Vol. 9, No. 5, 2021, pp. 204-212. doi: 10.11648/j.ajhr.20210905.19

Received: August 12, 2021; Accepted: September 7, 2021; Published: September 26, 2021

\begin{abstract}
Multidrug Resistance Tuberculosis (MDR-TB) is a major global public health crisis that needs great emphasis. Ethiopia is one of the 30 high TB, TB/HIV and drug resistant TB (DR-TB) burden countries globally and stands third among African countries. Treatment outcomes of MDR-TB are one of the essential performance indicators in evaluating the national TB control program. Such assessments however are limited at the facility and program level in Ethiopia. This study reported treatment outcomes and outcome predictors from a cohort of MDR-TB patients who were on WHO's longer treatment regimen at ALERT Hospital in Addis Ababa, Ethiopia. A retrospective assessment of patients' records was made and data were collected for the period 2011-to 2016 using structured checklist. Data were double entered to Red Cap and exported to SPSS v20 for analysis. Descriptive statistics was computed to get summary results, bivariate and multivariate analysis was used to identify factors which affect the dependent variables. Therefore a total of 363 (53.7\% males and $46.3 \%$ females) MDR-TB patients were included in the study. The mean age of the study participants was 29.6 years with the standard deviation of 11.2 years; the mean BMI was 18.5 with standard deviation of 3.0; and $78(21.5 \%)$ were HIV positive. The most prevalent side effects were gastric disturbance which includes epigastric pain/discomfort, indigestion, bloating and nausea/vomiting (46.25\%). Electrolyte abnormality occurred in $(39.53 \%)$ of the patents. Among all assessed patients, 147 (40.5\%) were cured, $132(36.4 \%)$ completed their treatment, treatment failure occurred in three patients $(0.8 \%), 46(12.7 \%)$ patients died and $35(9.6 \%)$ patients were lost to their follow-up. Overall, treatment success of $279(76.9 \%)$ was observed in this cohort. Female and employed patients who can generate regular income had favorable treatment outcome with (AOR: 2.5 ; 95\%CI: 1.4, 4.2), (AOR: 2.4; 95\%CI: 1.4, 4.0) respectively Patients with HIV were 50\% lower to have a favorable treatment outcome than HIV negative patients with (AOR: $0.5 ; 95 \%$ CI: $0.3,0.9)$. So, it has been concluded that treatment success rate was generally encouraging. However, significant numbers of patients were lost to follow up and died. Thus, targeted interventions towards addressing factors that affected treatment outcome in MDR-TB patient management should be made. Strengthened follow up should also be in place to reduce number of lost to follow up and deaths in MDR-TB patients.
\end{abstract}

Keywords: Multi Drug Resistant, Treatment Outcome, ALERT Hospital, Addis Ababa, Ethiopia 


\section{Introduction}

About a third of the world's population is estimated to be infected with tubercle bacilli and hence at risk of developing active disease and $90 \%$ of the cases is accounted for 30 high Tuberculosis (TB) burden countries in each year [1]. The drug-susceptible organisms are killed during sub-optimal treatment but the drug-resistant mutants gradually become an increasing proportion of the disease burden, and results in the emergence of a drug-resistant form of TB [2]. Therefore, drug-resistant TB is at large the consequence of human error related to the management of drug supply, patient management, prescription of chemotherapy, patient adherence and poor infection control practices [3].

In 2019 the global burden of multidrug- or rifampicin-resistant TB (MDR/RR-TB) as a share of the number of TB cases remains stable, an estimated 3.3\% of new and $18 \%$ of previously treated TB cases had MDR/RRTB with a total of $206030 \mathrm{MDR} / \mathrm{RR}-\mathrm{TB}$ patients were detected and notified, this increased by 10\% from 186883 in 2018. Among total cases 177099 patients were enrolled in treatment and a global treatment success rate was $57 \%$ [1].

Ethiopia is one of the 30 high TB, TB/HIV, and drug-resistant TB (DR-TB) burden countries globally and stands third among African countries and one of the three examples of high MDR-TB burden countries with relatively high TB treatment coverage that has higher treatment success rates for MDR/RR-TB ( $\geq 75 \%)$,[4]. Nationally a forty-six MDR-TB treatment initiation centers (TIC) are functional, with a corresponding increase in the number of treatment follow-up centers (TFCs) in 2016. RR/MDR-TB patients were put on second-line treatment were 700 with a total of 2820 cases enrolled in second-line drug since 2008 [5]. Treatment with the nationally constructed standardized a shorter treatment regimen is the preferred choice to treat the majority of RR-/MDR-TB patients in whom there is no additional risk or laboratory evidence of resistance or intolerance to medicines used in the regimen [4]. The 9-month-standardized shorter DR-TB treatment regimen includes four month $K m-M f x-P t o-C f z-Z-H^{H}-E$ and five month $M f x-C f z-Z-E$; it is believed to benefit patients and also the health system burden as it significantly shortens the need to administer treatment for up to two years [3].

ALERT Hospital is one of the treatment initiation centers in Ethiopia since 2011. This study aims to analyze the MDR-TB treatment outcome and associated factors of treatment cohorts at ALERT Hospital from 2011 to 2016. Since there was no previous assessment of treatment outcome in this facility this study provides baseline information that can be used by program managers and researchers.

\section{Methods}

\subsection{Study Area and Period}

The study was conducted at ALERT Hospital which has been administrated by federal democratic republic of Ethiopia's ministry of health. The MDR-TB treatment center was established and started operating as treatment initiation center in March 2011. The ALERT MDR-TB treatment ward has 24 bed capacities. Since then, about 428 patients have been served as inpatients and outpatient. Therefore this study has retrospectively analyzed patient data from 2011 to 2016 treatment cohort.

\subsection{Study Design}

Retrospective cross-sectional study design was used.

\subsection{Study Population}

All MDR-TB patients who had treatment outcome in the registration log book during 2011 to 2016.

\subsection{Inclusion Criteria}

All MDR-TB patients during 2011 to 2016 with records of treatment outcome those who start at and transferred in to ALERT hospital were included.

\subsection{Exclusion Criteria}

All MDR-TB patients who were transferred out to other health facilities and those treatment outcomes not evaluated were excluded.

\subsection{Sample Size and Sampling Technique}

This report considered a total of 428 MDR-TB patients who were on treatment during 2011 to 2016 at ALERT Hospital. Among those patients 363 of them had fulfilled the inclusion criteria and included in the study.

\subsection{Data Collection and Analysis}

Data were collected from patients' medical records using structured data collection tool which was adopted by the investigators from National MDR-TB registration log book and literatures The content of the format includes socio-demographic information, medical history such as sputum status at diagnosis and type of patient (new or retreatment), resistance type and co-morbid disease.

Data were double entered to Red Cap and exported to SPSS 20 for analysis. Descriptive statistics was computed to get summary results and bivariate logistic regression analysis was used to predict factors which affect dependent variables. Those variables with a $p$ value $\leq 0.25$ in bivariate analysis were candidates for multivariate analysis and stepwise method was used to test the model fitness. For each of the study variables, the association was estimated by the odds ratio (OR) together with the $95 \%$ confidence interval $(95 \% \mathrm{CI})$. The association between MDR-TB treatment outcome and explanatory variables was considered as statistically significant if a p-value less than 0.05 in multivariate analysis. 
Table 1. Socio demographic distribution of MDR-TB patients during 2011-2016 at ALERT Hospital ( $n=363)$.

\begin{tabular}{lll}
\hline Characteristics & Categories & N (\%) \\
\hline \multirow{2}{*}{ Age in years } & $\leq 18$ Years & $35(9.6)$ \\
& 19-65 Years & $324(89.3)$ \\
& $>65$ Years & $4(1.1)$ \\
Sex & Male & $195(53.7)$ \\
& Female & $168(46.3)$ \\
Employed & Yes & $225(62.0)$ \\
& No & $138(38.0)$ \\
Residence & Addis Ababa & $247(68.0)$ \\
& Out of Addis Ababa & $116(32.0)$ \\
\hline
\end{tabular}

\section{Results}

\subsection{Socio Demographic Description}

A total of 363 patients who had a complete record of treatment outcome were included in the study. The distribution of study participants by age group indicates 324 $(89.3 \%)$ were in the age group of $19-65$ years. The mean age of the study participants was 29.6 years with the standard deviation of 11.2 years. Out of the total study participants, 195 (53.7\%) were males. Study participants who lived in Addis
Ababa were 247 (68.0\%) and others were from outside of Addis Ababa (Table 1).

\subsection{Anthropometry and Medical History}

Majority of the participants had recorded weight and height, and the mean weight was $49.3 \mathrm{Kg}$ with the standard deviation of $10 \mathrm{Kg}$. The average BMI was 18.48 with standard deviation of 3. Regarding HIV status of the patients at enrollment, 78 (21.5\%) were positive and HIV status of 42 (11.6\%) patients was unknown. Sixty two $(79.5 \%)$ of HIV positive patients were enrolled in ART clinic. Diagnostic method used to confirm MDR-TB were Gene-X-pert 186 (51.2\%), Confirmed LPA 59 (16.3\%) and Confirmed Phenotypic 63 (17.4\%). Thirty nine (10.7\%) patients had co-morbid disease other than HIV and the most common co-morbid disease was diabetic mellitus 10 (26\%). Among MDR-TB patients who participated in the study, treatment was initiated to 321 (88.4\%) patients while they are admitted to the inpatient department.

Regarding smear results at enrollment, 198 (54.5\%), 127 (35\%) and $37(10.2 \%)$ patients were positive, negative and not evaluated respectively (Table 2).

Table 2. Anthropometry and Medical history of the MDR-TB patients who were on treatment during 2011-2016 at ALERT Hospital.

\begin{tabular}{|c|c|c|}
\hline Characteristics & Categories & $\mathbf{N}$ \\
\hline \multirow{4}{*}{ Weight $(n=362)$} & Range & 84 \\
\hline & Minimum & 6 \\
\hline & Maximum & 90 \\
\hline & Mean \pm SD & $49.3 \pm 10$ \\
\hline \multirow{4}{*}{ BMI $(n=355)$} & Range & 18.67 \\
\hline & Minimum & 10.71 \\
\hline & Maximum & 29.39 \\
\hline & Mean \pm SD & $18.48 \pm 3$ \\
\hline \multirow{3}{*}{ HIV status $(\mathrm{n}=363)$} & Negative & $243(66.9 \%)$ \\
\hline & Positive & $78(21.5 \%)$ \\
\hline & Unknown & $42(11.6 \%)$ \\
\hline \multirow{5}{*}{ Diagnostic Methods $(\mathrm{n}=363)$} & Confirmed X-pert & $186(51.2 \%)$ \\
\hline & Confirmed LPA & $59(16.3 \%)$ \\
\hline & Confirmed Phenotypic & $63(17.4 \%)$ \\
\hline & Not confirmed (clinically confirmed) & $7(1.9 \%)$ \\
\hline & Unknown & $48(13.2 \%)$ \\
\hline \multirow{2}{*}{ Resistance Type $(\mathrm{n}=363)$} & Mono-resistance & $31(8.5 \%)$ \\
\hline & Multidrug resistance & $332(91.5 \%)$ \\
\hline \multirow{2}{*}{ History of previous TB treatment $(\mathrm{n}=363)$} & Yes & $318(87.6 \%)$ \\
\hline & No & $45(12.4 \%)$ \\
\hline \multirow{2}{*}{ Co morbid disease other than HIV } & Yes & $39(10.7 \%)$ \\
\hline & No & $324(89.3 \%)$ \\
\hline \multirow{2}{*}{ Type of MDR-TB $(\mathrm{n}=361)$} & Pulmonary & $333(91.7 \%)$ \\
\hline & Extra Pulmonary & $28(7.7 \%)$ \\
\hline \multirow{2}{*}{ Treatment initiation model $(\mathrm{n}=357)$} & Inpatient & $321(88.4 \%)$ \\
\hline & Outpatient & $36(9.9 \%)$ \\
\hline \multirow{3}{*}{ Smear results at enrolment $(\mathrm{n}=362)$} & Positive & $198(54.5 \%)$ \\
\hline & Negative & $127(35.0 \%)$ \\
\hline & Not evaluated & $37(10.2 \%)$ \\
\hline
\end{tabular}

Among studied patients $87.6 \%$ patients were received anti TB drugs for one or more months in the past and again diagnosed with MDR-TB. Based on the previous treatment history patients were categorized as (figure 1 shows). 


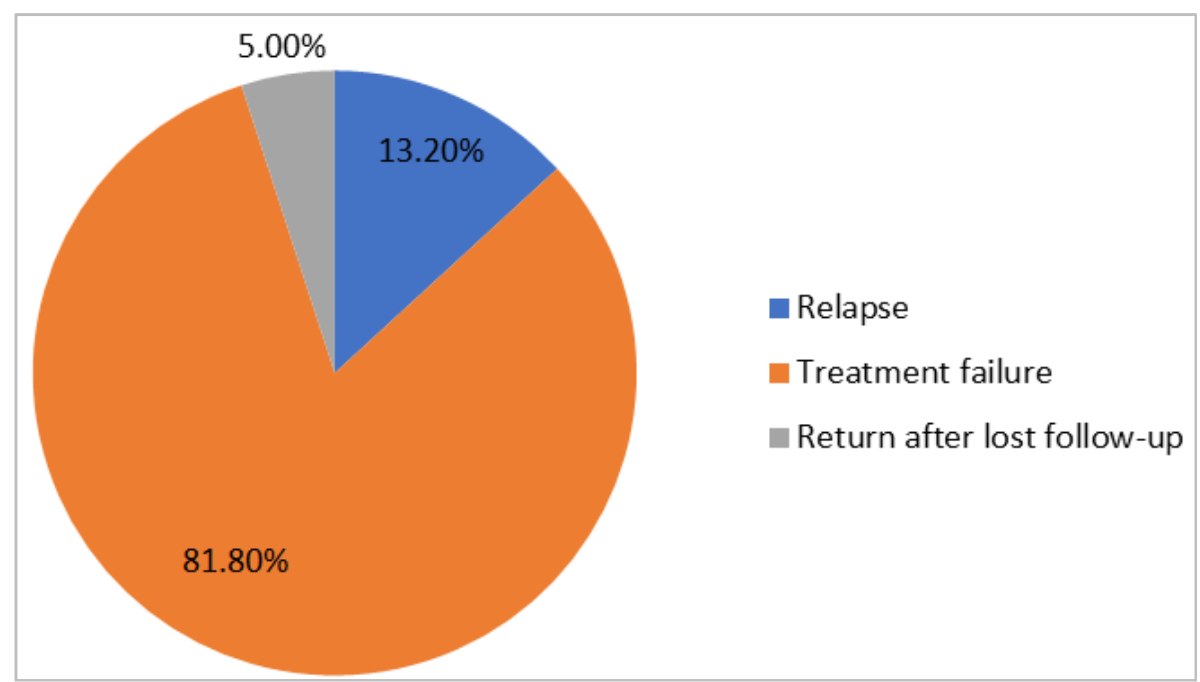

Figure 1. Registration group/category of MDR-TB patients who were on treatment during 2011-2016 at ALERT Hospital.

\subsection{Treatment and Side Effects}

Except for some changes in regimen made after reported the side effects $(1.9 \%)$, the standardized baseline SLD regimen was used for MDR-TB treatment with a median of five drugs.

Capreomycin $(86.5 \%)$ was the most common injectable used, followed by Kanamycin (8.8\%). The most common oral agents used as treatments were levofloxacin (90.9\%), cycloserine $\quad(89.5 \%), \quad$ Pyrazinamide $\quad(90.9 \%) \quad$ and
Prothionamide (63.1\%). Following initiation of the treatment majority of the patients developed at least one side effect mostly during the first month of treatment. Of them, the most prevalent side effects were gastric disturbance which includes epigastric pain/discomfort, indigestion, bloating and nausea/vomiting $(46.25 \%)$. Electrolyte abnormality occurred in $(39.53 \%)$ of the patents and other side effects were also recorded (Figure 2).

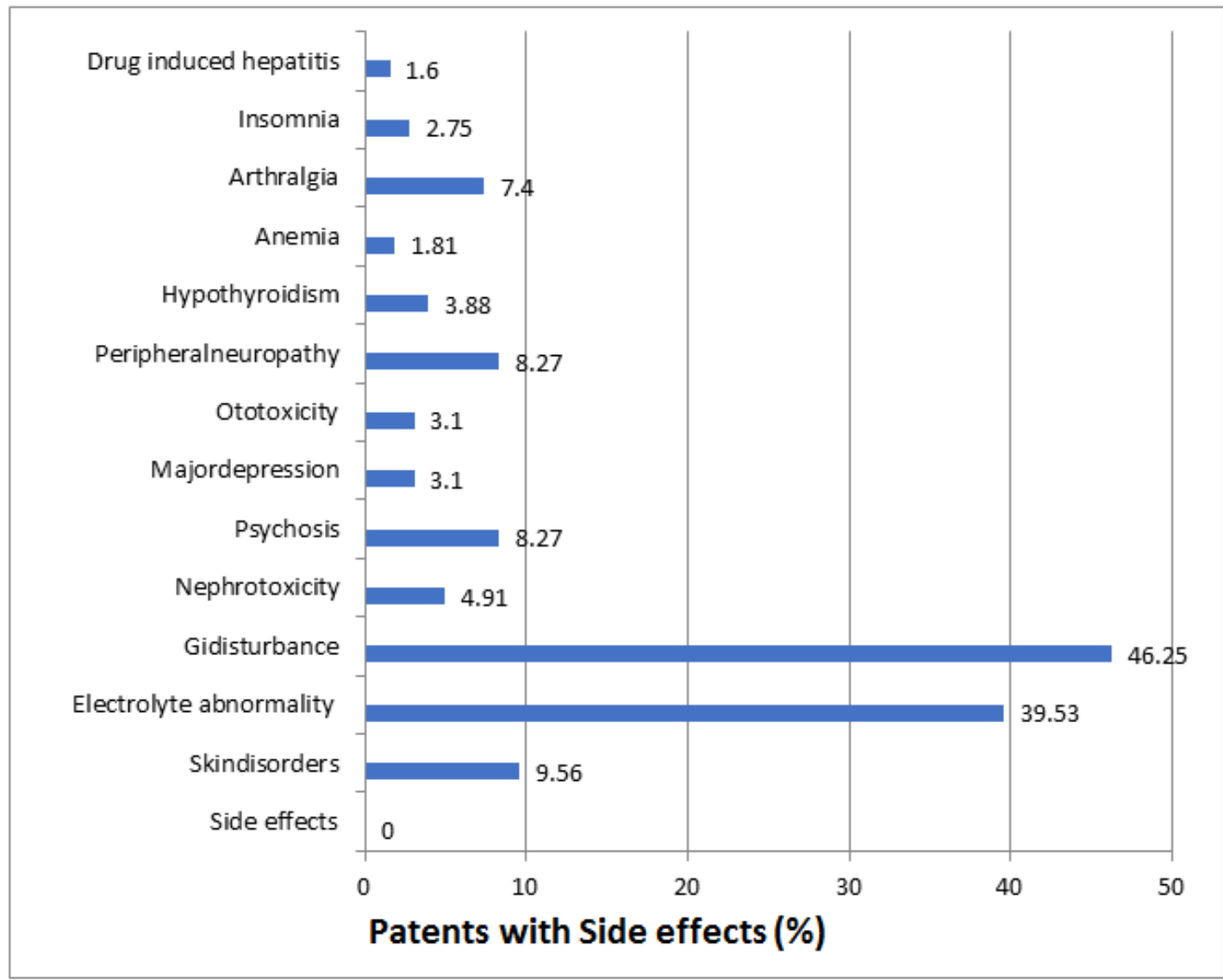

Figure 2. Frequency of side effects occurring during MDR-TB treatment at ALERT Hospital during 2011 to 2016. 


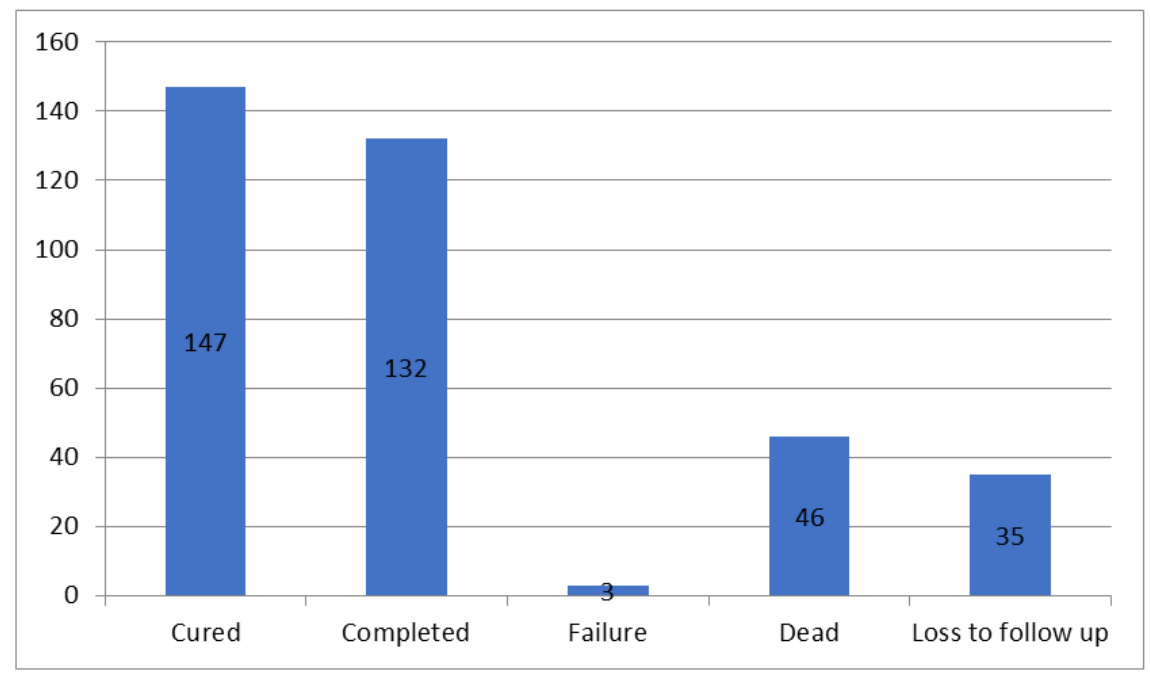

Figure 3. Treatment outcomes of patients who were on treatment for MDR-TB management during 2011-2016 at ALERT hospital.

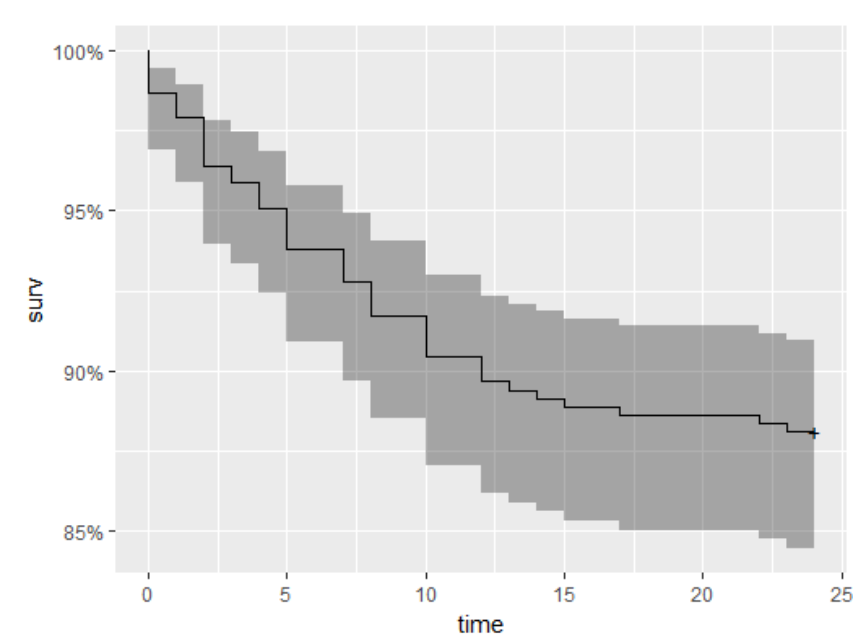

Figure 4. Kaplan-Meier curve showing the probability survival of MDR-TB patients since the initiation of treatment to the end during 2011-2016 at ALERT Hospital MDR-TB Treatment centre Addis Ababa Ethiopia.

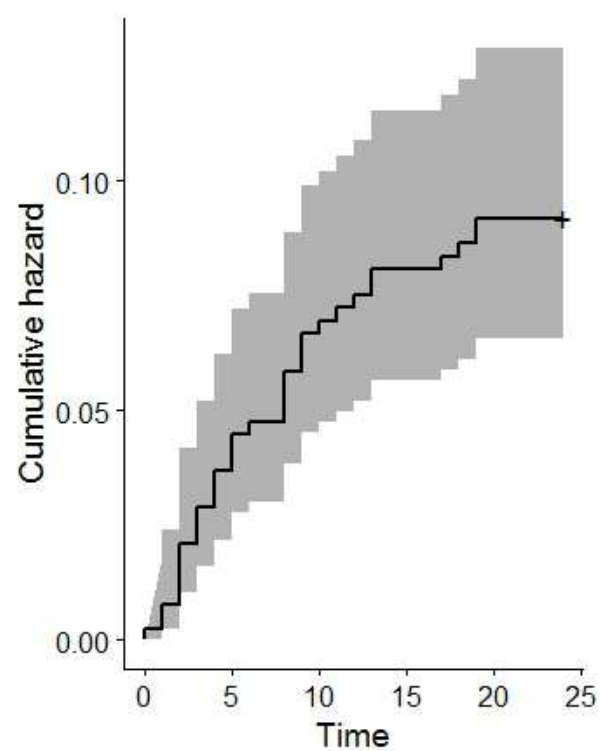

Figure 5. The hazard ratio showing the probability of patients being lost to follow up throughout the treatment period at ALERT Hospital during 2011 to 2016.

\subsection{Treatment Outcomes}

The treatment success rate among the assessed patients (i.e. $\mathrm{n}=363)$ was $279(76.9 \%)$ with $147(40.5 \%)$ cured and 132 (36.4\%) completed treatment. Treatment failure occurred in three patients $(0.8 \%), 46(12.7 \%)$ patients died during treatment and $35(9.6 \%)$ patients were lost to follow up. Therefore, unfavorable outcome occurred in $84(23.2 \%)$ patients (figure 3).

The survival of MDR-TB patients after treatment initiation with in a treatment period (time to death) was showing in (figure 4).

The hazard of Lost to follow up MDR-TB patients throughout treatment period, As we see the plot when the time increase the hazard to lost to follow up increase (figure 5).

\subsection{Factors Affecting MDR-TB Treatment Outcomes by Bivariate Analysis}

To examine factors associated with MDR-TB treatment outcome, first we were doing bivariate analysis in to order to select candidate variables for multivariate analysis. As showed in (Table 3 ).

\subsection{Factors Affecting MDR-TB Treatment Outcomes by Multivariate Analysis}

The relationship between MDR-TB treatment outcomes and socio-demographic characteristics showed that sex and occupation were statistically significantly associated with treatment outcomes. According to the multivariate analysis result, being female is 2.5 times more likely to have favorable treatment outcome (AOR: $2.5 ; 95 \%$ CI: 1.4, 4.2) compared to male. Similarly patients who were employed were 2.4 times more likely to have favorable treatment outcome than non-employed (AOR: 2.4; 95\%CI: 1.4, 4.0).

Patients with HIV were $50 \%$ lower to have a favorable treatment outcome than HIV negative patients with (AOR: 0.5; 95\%CI: 0.3, 0.9). However, patients with unknown HIV status were not statistically significantly associated with treatment outcome. 
Patients who were smear positive and smear negative at enrollment were 2.6 and 3.7 times more likely to have favorable treatment outcome (AOR: 2.6 ; $95 \% \mathrm{CI}: 1.2,5.6$ ),
(AOR: $3.7 ; 95 \% \mathrm{CI}: 1.6,8.7)$ respectively compared to those who were not evaluated (Table 4).

Table 3. Factors affecting MDR-TB treatment outcomes during 2011-2016 at ALERT hospital.

\begin{tabular}{|c|c|c|c|c|}
\hline \multirow{2}{*}{ Characteristics } & \multirow{2}{*}{ Category } & \multicolumn{2}{|l|}{ Treatment outcome } & \multirow{2}{*}{ COR $(95 \% \mathrm{CI})$} \\
\hline & & Unfavorable $(n=84)$ & Favorable $(n=279)$ & \\
\hline \multirow{3}{*}{ Age in Years } & $\leq 18$ & $7(20 \%)$ & $28(80 \%)$ & $12.0(1.1,133)$ \\
\hline & $19-65$ & $74(22.8 \%)$ & $250(77.2 \%)$ & $10.1(1.1,98.8)$ \\
\hline & $>65$ & $3(75 \%)$ & $1(25 \%)$ & 1 \\
\hline \multirow{2}{*}{ Sex } & Male & $58(29.7 \%)$ & $137(70.3)$ & 1 \\
\hline & Female & $26(15.4 \%)$ & $142(84.6)$ & $2.3(1.4,3.9)$ \\
\hline \multirow{2}{*}{ Occupation } & Yes & $40(17.7 \%)$ & $185(84.3)$ & $2.2(1.3,3.6)$ \\
\hline & No & $44(31.8 \%)$ & $94(68.2 \%)$ & 1 \\
\hline \multirow{2}{*}{ Residence } & Addis Ababa & $54(21.8 \%)$ & $193(78.2 \%)$ & $1.3(0.7,2.1)$ \\
\hline & Out of Addis & $30(25.8 \%)$ & $86(74.2 \%)$ & 1 \\
\hline \multirow{3}{*}{ HIV Status } & Negative & $50(20.6 \%)$ & $193(79.4 \%)$ & 1 \\
\hline & Positive & $26(33.3 \%)$ & $52(76.7 \%)$ & $0.5(0.3,0.9)$ \\
\hline & Unknown & $8(19 \%)$ & $34(81 \%)$ & $1.1(0.5,2.5)$ \\
\hline \multirow{5}{*}{ Diagnostic Method } & Confirmed X-pert & $43(23.1 \%)$ & $143(76.9 \%)$ & 1 \\
\hline & Confirmed LPA & $12(20.3 \%)$ & $47(79.7 \%)$ & $1.2(0.6,2.4)$ \\
\hline & Confirmed Phenotypic & $16(25.4 \%)$ & $47(74.6 \%)$ & $0.9(0.5,1.7)$ \\
\hline & Not confirmed (clinically confirmed) & $1(14.3 \%)$ & $6(85.7 \%)$ & $1.8(0.2,15.4)$ \\
\hline & Unknown & $12(25 \%)$ & $36(75 \%)$ & $0.9(0.4,1.9)$ \\
\hline \multirow{2}{*}{$\begin{array}{l}\text { History of Previous TB } \\
\text { treatment }\end{array}$} & No & $12(26.7 \%)$ & $33(73.3 \%)$ & $1.2(0.6,2.5)$ \\
\hline & Yes & $72(22.6 \%)$ & $246(77.4 \%)$ & 1 \\
\hline \multirow{2}{*}{ Co morbidity } & No & $71(21.9 \%)$ & $253(78.1 \%)$ & $1.8(0.8,3.6)$ \\
\hline & Yes & $13(33.3 \%)$ & $26(66.7 \%)$ & 1 \\
\hline \multirow{2}{*}{ Type of MDR-TB } & Pulmonary & $77(23.1 \%)$ & $256(76.9 \%)$ & $1.2(0.5,2.7)$ \\
\hline & Extra-Pulmonary & $7(25 \%)$ & $21(75 \%)$ & 1 \\
\hline \multirow{2}{*}{ First treated A } & Inpatient & $73(22.7 \%)$ & $248(77.3 \%)$ & $1.1(0.5,2.5)$ \\
\hline & Out patient & $9(25 \%)$ & $27(75 \%)$ & \\
\hline \multirow{3}{*}{ Smear Result } & Positive & $48(24.2 \%)$ & $150(75.8 \%)$ & $2.1(1.1,4.4)$ \\
\hline & Negative & $21(16.5 \%)$ & $106(83.5 \%)$ & $3.4(1.5,7.7)$ \\
\hline & Not evaluated & $15(40.5 \%)$ & $22(59.5 \%)$ & 1 \\
\hline \multirow{4}{*}{ BMI } & $<16$ & $16(25 \%)$ & $48(75 \%)$ & 1 \\
\hline & $>=16-18.49$ & $22(18.3 \%)$ & $98(81.7 \%)$ & $1.4(0.7-3.0)$ \\
\hline & $18.5-24.99$ & $37(23.5 \%)$ & $120(76.5 \%)$ & $1.1(0.6,2.2)$ \\
\hline & $25-29.99$ & $3(25 \%)$ & $9(75 \%)$ & $1.0(0.2,4.1)$ \\
\hline
\end{tabular}

Table 4. Identified variables which affect MDR-TB treatment outcomes during 2011-2016 at ALERT Hospital.

\begin{tabular}{|c|c|c|c|c|c|c|}
\hline \multirow{2}{*}{ Characteristics } & \multirow{2}{*}{ Category } & \multicolumn{2}{|c|}{ Treatment outcome } & \multirow{2}{*}{ COR $(95 \%$ CI) } & \multirow{2}{*}{ AOR (95\%CI) } & \multirow{2}{*}{ P Value } \\
\hline & & Unfavorable & Favorable & & & \\
\hline \multirow{2}{*}{ Sex } & Male & 58 & 137 & 1 & 1 & \\
\hline & Female & 26 & 142 & $2.3(1.4,3.9)$ & $2.5(1.4,4.2)$ & 0.001 \\
\hline \multirow{3}{*}{ Employed } & Yes & 40 & 185 & $2.2(1.3,3.6)$ & $2.4(1.4,4.0)$ & 0.001 \\
\hline & No & 44 & 94 & 1 & 1 & \\
\hline & Negative & 50 & 193 & 1 & 1 & \\
\hline \multirow[t]{2}{*}{ HIV Status } & Positive & 26 & 52 & $0.5(0.3,0.9)$ & $0.5(0.3,0.9)$ & 0.03 \\
\hline & Positive & 48 & 150 & $2.1(1.1,4.4)$ & $2.6(1.2,5.6)$ & 0.019 \\
\hline \multirow[t]{2}{*}{ Smear Result } & Negative & 21 & 106 & $3.4(1.5,7.7)$ & $3.7(1.6,8.7)$ & 0.002 \\
\hline & Not evaluated & 15 & 22 & 1 & 1 & \\
\hline
\end{tabular}

\section{Discussion}

MDR-TB treatment outcome of ALERT hospital from 2011 to 2016 was described in this study. The treatment success rate was $363(76.9 \%)$ and unfavorable outcome was observed on $84(23.2 \%)$ patients.

The treatment success rate observed in this study was higher than most MDR-TB burden countries reported in 2016, namely; Angola 74\% (116), Bangladesh 75\% (686),
Brazil 52\% (759), China 55\% (2184), India 46\% (15 906), Mozambique 52\% (313), Philippines 49\% (1 968), South Africa $48 \%$ (10614) but lesser than that of Kenya $82 \%$ (266) and Nigeria 77\% (339) [2].

According to WHO report in 2020, treatment success rate for MDR/RR-TB in Ethiopia was $>75 \%$, although a better outcome observed in this study it was less than the WHO set target i.e. at least $90 \%$ treatment success rate [4]. Therefore, these findings may further suggest the need for strengthening the programmatic MDR-TB management including searching 
for a better treatment regimen such as introducing WHO recommended shorter treatment regimen in Ethiopia [6].

The treatment outcome in the current report was comparable to the report from cohort of 2009-2014 from St Peter's and University of Gonder hospitals combined study [7]. Compared to our report from this study, the cured patients were less by $24.2 \%$ ( $40.5 \%$ vs. $64.7 \%$ ) in our report. However, such variation may be accounted to sample size differences between the two cohorts, the former being significantly larger.

Regarding patients who completed treatment, our result was higher than St. Peter's study by $22.5 \%$ (36.4\% vs. $13.9 \%$ ) [7]. This variation could be explained that treatment completed patients in our study had no bacteriological confirmation but clinically confirmed as treatment completed. Moreover this variation might happen due to laboratory facilities.

More deaths and lost to follow up patients were recorded in our study than St. Peter's study [7] (12.7\%, vs. 13.9\%), (9.6\% vs. $5.9 \%$ ) respectively. This might be due to sample size variation and socio demographic difference.

Our study showed that female participants were more likely to have good treatment outcome than males with (AOR: 2.5; 95\%CI: 1.4, 4.2). This finding is consistent with studies conducted in Ukraine and South Africa (AOR: 2.3; 95\%CI: $1.2,4.4)[8,9]$. This might be due to social and behavioral factor differences between male and female patients, however it needs further study.

Regarding occupations of the participants, employed patients have favorable treatment outcomes than unemployed with (AOR: 2.4; 95\%CI: 1.4, 4.0). This finding is in line with a study conducted in Ukraine that reported the rate of poor outcome is significantly higher among unemployed patients AOR: 1.97; 95\% CI: $1.03-3.78$ ) [8]. This might be the fact that related to the huge adverse economic impact of the disease on patients due to the long duration and complexity of the treatment $[10,11]$.

MDR-TB/HIV co-infection was documented to contribute to poor outcome of MDR-TB treatment in different studies [7, 12, 13]. Our study also found that MDR-TB patients who are living with HIV were less likely to have a favorable treatment outcome and it was consistent with a report from a study conducted in St. Peter's TB Specialized Hospital in 2015 [14]. This implies that due to the immunity compromising nature of HIV infection, it is difficult to diagnose and start treatment early. Even after treatment started; related to pill burden, increase in adverse effect, drug-to-drug interaction, and immune reconstitution inflammatory syndrome may also contribute to poor treatment outcome [15]. Among unknown HIV status patients in our study majority of them $(81 \%)$ had favorable treatment outcomes this might be accounted to they had negative status.

Smear result of MDR-TB patients was associated with treatment outcome. Patients who were smear positive at enrollment were more likely to have favorable treatment outcome than those who were not evaluated. A study conducted in Bulgaria also reported that sputum smear positivity at the start of treatment was the strongest predictor for successful treatment outcomes [16]. This implies that it is easy to determine patient progress and take action early if smear result is known at the beginning of the treatment.
A study conducted in Georgia in 2014 to compare MDR-TB treatment outcome among patients with and without co-morbidities showed that patients with co-morbidities had significantly lower favorable treatment outcomes [17]. In our study, the favorable treatment outcome in patients without co-morbidities was not statistically associated. Such discrepancies might be accounted to the variation between the study participants' socio demography, the type of comorbid disease and study settings. However, it needs further investigation.

Studies reported in China, Bulgaria and Ukraine [18, 16, $8,19]$ indicated that previous TB treatment was associated with unsuccessful treatment outcomes. Our study however showed no effect and this is supported by other study conducted in Switzerland [20]. This might be due to variation as majority of our participants were previously treated with anti-TB.

Our study tried to see the effect of patient care models on treatment outcomes. However the findings showed that there were no significant relationships. This finding was in line with similar studies in Namibia and a systematic review which were done to show the effectiveness of hospital and ambulatory based care of MDR-TB [21-24].

To make a convenient patient management and follow-up of MDR-TB case, the management has been shifted from the hospitalized model of care to ambulatory model by the Ethiopia National Tuberculosis Control program based on WHO recommendation [4, 25]. Therefore our finding strengthens the quality of evidences available that MDR-TB patients can be treated using mainly ambulatory care.

\section{Conclusion}

More than three-fourth of the MDR-TB patients had experienced favorable outcomes but it was below the WHO target level of $\geq 90 \%$. There were high proportion of death and lost to follow up noticed in this study.

MDR-TB patients with HIV infection and unemployed had unfavorable treatment outcomes whereas female patients and patients who had smear result at enrollment had favorable treatment outcomes.

According to the finding of this study patient care model had no significant effect on the treatment outcome. Therefore, outpatient care can equally be used for the treatment initiation in MDR-TB patients in resource limited countries such as Ethiopia as long as public protection particularly in sputum non-converted patients are guaranteed through public health education, counseling and social support.

\section{Declarations}

\section{Ethics Approval and Consent}

Ethical approval obtained from IRB of Jimma University, Reference No. IHRPGD/834/17 and AHRI/ALERT Ethics Review Committee; consent waiver given by AHRI/ALERT Ethics Review Committee. 


\section{Consent for Publication}

Not applicable.

\section{Availability of Data and Materials}

The datasets generated and analysed during the current study are not publicly available due access restriction AHRI Red Cap data base policy but are available from the corresponding author on reasonable request.

\section{Competing Interests}

The authors declare that they have no competing interests.

\section{Authors' Contributions}

All authors discussed the results and contributed to the final manuscript.

N. A wrote the manuscript with support from M. T.

K. W., H. J., O. A., S. A, E. T., M. T. and N. A. contributed to the interpretation of the results.

N. A. took the lead in writing the manuscript.

H. j and N. A. designed the computational framework and analysed the data.

M. T., S. A. and N. A. performed the analysis, drafted the manuscript and designed the figures.

H. J., K. W., M. T. and N. A. contributed to the design and implementation of the research, to the analysis of the results.

\section{References}

[1] World Health Organization. Global tuberculosis report 2020 [Internet]. Geneva: World Health Organization; 2020 [cited 2021 Sep 3]. Available from: https://apps.who.int/iris/handle/10665/336069.

[2] World Health Organization. Regional Office for Europe, Solomonia N, Dadu A, Ehsani S, Sereda Y, Shah S, et al. Compliance of drug-resistant tuberculosis treatment regimens with drug susceptibility testing results and its association with treatment outcomes in Georgia. Public Health Panor. 2019; 5 (4): 515-24.

[3] World Health Organization. Regional Office for Europe. Final report on implementation of the Tuberculosis Action Plan for the WHO European Region 2016-2020 [Internet]. Copenhagen: World Health Organization. Regional Office for Europe; 2020 [cited 2021 Sep 6]. Available from: https://apps.who.int/iris/handle/10665/337926.

[4] FDREMOH. GUIDELINES FOR MANAGEMENT OF TB, DR-TB AND LEPROSY IN ETHIOPIA. SIXTH EDITION. Addis Ababa; 2018. 217 p.

[5] Federal Democratic Republic of Ethiopia Ministry of Health. NATIONAL STRATEGIC PLAN TUBERCULOSIS AND LEPROSY CONTROL 2006-2013 EC (2013/14-2020). Addis Ababa Ethiopia; 2018. 88 p.

[6] Sotgiu G, Tiberi S, Centis R, D'Ambrosio L, Fuentes Z, Zumla A, et al. Applicability of the shorter 'Bangladesh regimen' in high multidrug-resistant tuberculosis settings. Int J Infect Dis. 2017 Mar; 56: 190-3.
[7] Meressa D, Hurtado RM, Andrews JR, Diro E, Abato K, Daniel $\mathrm{T}$, et al. Achieving high treatment success for multidrug-resistant TB in Africa: initiation and scale-up of MDR TB care in Ethiopia - an observational cohort study. Thorax. 2015 Dec; 70 (12): 1181-8.

[8] Aibana O, Bachmaha M, Krasiuk V, Rybak N, Flanigan TP, Petrenko V, et al. Risk factors for poor multidrug-resistant tuberculosis treatment outcomes in Kyiv Oblast, Ukraine. BMC Infect Dis [Internet]. 2017 Dec [cited 2017 Aug 5]; 17 (1). Available from: http://bmcinfectdis.biomedcentral.com/articles/10.1186/s1287 9-017-2230-2.

[9] Elliott E, Draper HR, Baitsiwe P, Claassens MM. Factors affecting treatment outcomes in drug-resistant tuberculosis cases in the Northern Cape, South Africa. Public Health Action. 2014 Sep 21; 4 (3): 201-3.

[10] Morris MD, Quezada L, Bhat P, Moser K, Smith J, Perez H, et al. Social, economic, and psychological impacts of MDR-TB treatment in Tijuana, Mexico: a patient's perspective. Int $\mathrm{J}$ Tuberc Lung Dis. 2013 Jul 1; 17 (7): 954-60.

[11] Management Sciences for Health. Costs faced by multi-drug resistant tuberculosis patients during diagnosis and treatment. Report from a pilot study in Ethiopia. Management Sciences for Health; 2014 Jan p. 48.

[12] Farley JE, Ram M, Pan W, Waldman S, Cassell GH, Chaisson RE, et al. Outcomes of Multi-Drug Resistant Tuberculosis (MDR-TB) among a Cohort of South African Patients with High HIV Prevalence. Goletti D, editor. PLoS ONE. 2011 Jul 22; 6 (7): e20436.

[13] Phuong NTM, Nhung NV, Hoa NB, Thuy HT, Takarinda KC, Tayler-Smith K, et al. Management and treatment outcomes of patients enrolled in MDR-TB treatment in Viet Nam. Public Health Action. 2016 Mar 21; 6 (1): 25-31.

[14] Tsegaye Tulu, Mesfin Haile Kahissay. Assessment of Multidrug Resistance Tuberclosis Treatment Outcome in St. Petre's Tuberclosis Specialized Hospital, Addis Ababa, Ethiopia. Malays J Med Biol Res. 2014 Dec 30; 1, No 3 (2014): 97-107.

[15] Biruk M, Yimam B, Abrha H, Biruk S, Amdie FZ. Treatment Outcomes of Tuberculosis and Associated Factors in an Ethiopian University Hospital. Adv Public Health. 2016; 2016: $1-9$.

[16] Milanov V, Falzon D, Zamfirova M, Varleva T, Bachiyska E, Koleva A, et al. Factors associated with treatment success and death in cases with multidrug-resistant tuberculosis in Bulgaria, 2009-2010. Int J Mycobacteriology. 2015 Jun; 4 (2): 131-7.

[17] Marina Kikvidze, Lali Ikiashvili. Comorbidities and MDR-TB treatment outcomes in Georgia- 2009-11 cohort. Eur Respir J. 2014.

[18] Tang S, Tan S, Yao L, Li F, Li L, Guo X, et al. Risk Factors for Poor Treatment Outcomes in Patients with MDR-TB and XDR-TB in China: Retrospective Multi-Center Investigation. Wilkinson KA, editor. PLoS ONE. 2013 Dec 5; 8 (12): e82943.

[19] Huang F-L, Jin J-L, Chen S, Zhou Z, Diao N, Huang H-Q, et al. MTBDRplus results correlate with treatment outcome in previously treated tuberculosis patients. Int J Tuberc Lung Dis. 2015 Mar 1; 19 (3): 319-25. 
[20] Helbling P, Altpeter E, Egger J, Zellweger J. Treatment outcomes of multidrug-resistant tuberculosis in Switzerland. Swiss Med Wkly [Internet]. 2014 Dec 4 [cited 2017 Aug 5]; Available from: http://doi.emh.ch/smw.2014.14053.

[21] European Centre for Disease Prevention and Control. Rapid Risk Assessment: Healthcare system factors influencing treatment results of MDR TB patients. Stockholm: European Centre for Disease Prevention and Control, 2014 p. 6.

[22] Bassili A, Qadeer E, Floyd K, Fitzpatrick C, Fatima R, Jaramillo E. A Systematic Review of the Effectiveness of Hospital- and Ambulatory-Based Management of Multidrug-Resistant Tuberculosis. Am J Trop Med Hyg. 2013 Aug 7; 89 (2): 271-80.

[23] International Union Against, Tuberculosis and Lung Disease (The Union). 46th World Conference on Lung Health of the International Union Against Tuberculosis and Lung Disease. In:
The Official Journal of the International Union Against Tuberculosis and Lung Disease. CAPE TOWN, SOUTH AFRICA: The International Journal of Tuberculosis and Lung Disease; 2015. p. S S 1-S 588.

[24] Waheed Z, Irfan M, Haque AS, Khan MO, Zubairi A, ul Ain N, et al. Treatment Outcome of Multi-Drug Resistant Tuberculosis Treated As Outpatient in a Tertiary Care Center. Pak J Chest Med [Internet]. 2011 [cited 2017 Aug 6]; 17 (3). Available from: http://pjcm.net/index.php/pjcm/article/view/121.

[25] Kibret KT, Moges Y, Memiah P, Biadgilign S. Treatment outcomes for multidrug-resistant tuberculosis under DOTS-Plus: a systematic review and meta-analysis of published studies. Infect Dis Poverty [Internet]. 2017 Dec [cited 2017 Aug 5]; 6 (1). Available from: http://idpjournal.biomedcentral.com/articles/10.1186/s40249-0 16-0214-x. 